\title{
Community rehabilitation for schizophrenia patients
}

To the Editor: I read the editorial entitled 'Community rehabilitation for schizophrenia patients: Is it feasible in South Africa?" with interest, but was very surprised to see that no mention was made of the Assertive Community Treatment Programme that has been running in the Western Cape since 2007.

The ACT teams lone team based at each of the three state psychiatric hospitals) have now been functioning for nearly 4 years, utilising a cost-effective model adapted to the South African situation. A research programme also ran concurrently during the first 2 years of the initiative, with results clearly supporting the efficacy of the ACT programme.

To date four articles have been published ${ }^{25}$ describing the modus operandi as well as reporting on the successful outcomes. From our side we therefore fully support the concept of a hospital-based community outreach programme, and believe that the Western Cape ACT initiative has already shown that such a system is very appropriate to our setting.

\section{Ulla Botha}

Senior Specialist and ACT Co-ordinator, Stikland Hospital Bellville, W Cape

\footnotetext{
Betancourt $O A$, Herrera MM. Community rehabilitation for schizophrenia patients: Is it feasible in South Africa? South African Journal of Psychiatry 2010; 16(3):66-68.

2. Botha UA, Koen L, Joska JA, Hering LM, Oosthuizen PP. Assessing the efficacy of a modified assertive community-based treatment programme in a developing country. BMC Psychiatry 2010;10:73

3. Botha UA, Koen L, Joska JA, et al. The revolving door phenomenon in psychiatry: comparing low-frequency and high-frequency users of psychiatric inpatient services in a developing country. Soc Psychiatry Psychiatr Epidemiol 2010;45(4):46 1-468.

4. Lund C, Oosthuizen P, Flisher AJ, et al. Pathways to inpatient mental health care among people with schizophrenia spectrum disorders in South Africa. Psychiatr Serv 2010;61(3):235-240.

5. Botha U, Koen L, Oosthuizen P, Joska J, Hering L. Assertive community treatment in the South African context. African Journal of Psychiatry 2008; 1 1(4):272-275.
} 